\title{
Nglebur Laras
}

\section{Teteh Dayatami ${ }^{1}$}

\begin{abstract}
The concept of nglebur laras this time is interpreted as the concept of melting the barrel in all situations and conditions in the Karawitan art activity area. The concept can be interpreted as a draw concept, it will not draw if you forget the barrel between them (between the barrel of the pelog and between the barrel of the slendro). Everything always passes between them. Between the barrel of the pelog and the barrel of slendro, half pelog and half slendro it is the behavior of the barrel event which cannot be guessed its existence in the strains of Karawitan's gendhing. Whatever form of sound character is displayed by the barrel of pelog, slendro, and between the two, the fact is that the phenomenon of mixed barrel beating is still called the class of the barrel (of course), and on the concept of karawitan (in particular). The spread of this mixed barrel work is indeed very rapid, especially in the Java area. Pengrawit social society that often makes works by processing mixed tunings is now very spoiled, the habit of looking for the attention of the general public, making the general public become excited by the existence of mixed barrel work, considered uniqueness that is not boring. On the contrary, if the general public understands the condition and essence of the barrel work in general, it will be a suspicion that might be considered damaging the standard and so on.

The actualization sought was to create an archipelago music art work with a gender instrument by mixing the duality of the barrel, namely pelog and slendro in one instrument. This Nglebur Laras has multiple interpretations. Nglebur is a term used by gamelan makers / craftsmen, which means the activity of mixing raw materials (iron, tin, copper) into liquid. Nglebur can be interpreted as melting mix or which can also be called mbesot. Nglebur is the main ingredient in making gamelan because iron, tin and copper which are still hard must be cooked first to the point of melting. Then the barrel is the essence that plays an important role in the world of Karawitan. Laras has two special concepts called pelog and slendro. These two different concepts certainly have different characters. Laras is one of the important pieces of furniture. Laras consists of two groups, namely, pelog barrel and slendro barrel. Both types of barrel are one of the two main elements that characterize music. Laras in the world of karawitan has three plural meanings, namely, first; something that is (comfortable) or delicious to be heard or lived, second; namely the sound that has been determined the number of frequencies (penunggul, gulu, dhadha, pelog, lima, nem and item). The third meaning is the scale or scale, which is the arrangement of the notes in the number of sequences and the interval patterns of the tones have been determined. The taste is related to tastes like the expression Rahayu Supanggah in his book Bothekan Karawitan I that 'the barrel is very close to taste, taste can be formed by culture, including local traditions and habits'. The two words that are deliberately combined through all the 'combinations' that the author means are infallibility or an interesting possibility of all possibilities that might occur. It can also be understood that the title of the Nglebur Laras is a synergy or a fusion of all the anxieties in human social culture and social culture of Javanese music (especially the Javanese Gamelan).

Keywords: Nglebur, barrel, and unity.
\end{abstract}

${ }^{1}$ Mahasiswa S-2 Program Pascasarjana ISI Yogyakarta. 


\begin{abstract}
Abstrak
Konsep nglebur laras kali ini dimaknai sebagai konsep peleburan laras dalam segala situasi dan kondisi diwilayah kegiatan seni Karawitan. Konsep tersebut bisa diartikan konsep imbang, tidak akan imbang jika melupakan laras diantaranya (diantara laras pelog dan diantara laras slendro). Segala hal selalu melewati di-antara-nya. Antara laras pelog dan laras slendro, setengah pelog dan setengah slendro itu adalah perilaku peristiwa laras yang tidak bisa ditebak keberadaannya dalam alunan gendhing Karawitan. Apa pun bentuk karakter bunyi yang ditampilkan oleh laras pelog, slendro, dan diantara keduanya, faktanya fenomena menabuh laras campur masih disebut golongan dari laras (tentunya), dan pada konsep karawitan (khususnya). Penyebaran garap laras campuran ini memang sangat pesat perkembangannya, terutama di area Jawa. Sosial masyarakat pengrawit yang kerap membuat karya dengan mengolah laras campur kini memang sangat manja, kebiasaan mencari perhatian masyarakat umum, membuat masyarakat umum tersebut menjadi semangat dengan adanya garap laras campur, dianggap keunikan yang tidak membosankan. Demikian sebaliknya, jika masyarakat umum paham dengan kondisi dan esensi tentang garap laras pada umunya tersebut, justru akan adanya kecurigaan yang mungkin dapat dianggap merusak pakem dan seterusnya.

Aktualisasi yang diupayakan yakni membuat karya seni musik nusantara dengan media instrumen gender dengan mencampur dualitas laras yaitu, pelog dan slendro dalam satu instrumen. Nglebur Laras ini memiliki multi-interpretasi. Nglebur merupakan sebuah istilah yang digunakan oleh pembuat/pengrajin gamelan, yang artinya kegiatan penyampuran bahan-bahan mentah (besi, timah, tembaga) menjadi cair. Nglebur bisa diartikan melebur campuran atau yang dapat juga disebut dengan mbesot. Nglebur menjadi utama dalam pembuatan gamelan karena besi, timah, dan tembaga yang masih keras harus dimasak terlebih dahulu hingga menuju titik cair. Kemudian laras adalah esensi yang berperan penting dalam dunia Karawitan. Laras memiliki dua konsep khusus yang disebut pelog dan slendro. Dua konsep yang berbeda ini tentunya memiliki karakter-karakter yang berbeda. Laras merupakan salah satu perabot garap yang cukup penting. Laras terdiri dari dua kelompok yaitu, laras pelog dan laras slendro. Kedua jenis laras tersebut adalah satu dari dua unsur utama yang mencirikan karawitan. Laras dalam dunia karawitan memiki tiga makna jamak yaitu, pertama; sesuatu yang (bersifat) 'enak atau nikmat untuk didengar atau dihayati, kedua; yaitu suara yang telah ditentukan jumlah frekuensinya (penunggul, gulu, dhadha, pelog, lima, nem dan barang). Makna yang ketiga adalah tangga nada atau scale, yaitu susunan nada-nada yang jumlah urutan dan pola interval nadanadanya telah ditentukan. Rasa tersebut berkaitan dengan selera seperti ungkapan Rahayu Supanggah dalam bukunya Bothekan Karawitan I bahwa 'laras memang sangat erat dengan rasa, selera rasa dapat terbentuk oleh budaya, termasuk tradisi dan kebiasaan lokal'. Kedua kata yang sengaja digabungkan melalui segala 'gabungan' yang penulis maksud adalah keserbajadian atau kebolehjadian yang menarik segala kemungkinan yang mungkin terjadi. Boleh juga dipahami bahwa judul Nglebur Laras ini sebagai sinergi atau peleburan segenap rasa kegelisahan dalam sosial budaya manusia dan sosial budaya musik Jawa (khususnya Gamelan Jawa).
\end{abstract}

Kata kunci: Nglebur, laras, dan kesatuan. 


\section{Pendahuluan}

Pengalaman hidup seseorang bisa membuat sensitifnya suasana hati. Jika dengan pebgalaman buruk, maka hal tersebut membawa pikiran kearah yang (kadang) negatif. Tidak menolak kemungkinan (juga) bahwa sisi pengalaman tersebut dapat menjadi suatu gagasan ide membuat sebuah karya seni yang baik. Penulis memiliki satu gagasan ide atau pengalaman hidup yang dianggap tepat untuk menjadi penggantar sebuah karya seni musik (khususnya).

Sekitar tahun 2012 penulis membuat karya komposisi karawitan dengan judul 'Ibu Pertiwi Laras Campur' (gabungan laras pelog dan laras slendro). Pada karya ini penulis mengadaptasi karya Ki Narto Sabdo yang berjudul ketawang Ibu Pertiwi laras pelog pathet 6 (nem) hanya pada bagian gerong. Gerong atau gerongan adalah suatu tembang yang disuarakan oleh wiraswara (pelaku tembang laki-laki) pada saat gending melantun. Pada tahun yang sama, penulis juga membuat karya yang berjudul YANG-yangan, arti judul disini yang dimaksud adalah pacaran. Karya ini menggunakan dua entitas laras yakni pelog pada gamelan Gong Kebyar dan laras slendro pada gamelan Jawa. Tetap dalam ranah pencampuran laras, akan tetapi disini penulis mendapatkan tantangan baru yaitu mengolah rasa laras pelog pada gamelan Gong Kebyar etnis Bali. Lalu pada tahun selanjutnya awal tahun 2014, penulis kembali berkarya dengan tajuk 'Aku, Kamu adalah Kita'. Karya tersebut yakni terusan dari konsep campuran pathet, kemudian gabungan dari lintas etnis, mengerucut pada titik tahun 2014 penulis menggabungkan segalanya dalam satu garapan musik etnis. Hingga akhir tahun 2014 - tahun 2015 awal penulis menggagas konsep nglebur lebih dalam dan serius. Gender of gender (instrumen) adalah konsep nglebur yang penulis sudah angankan sejak lama dan akhirnya terwujud walaupun belum maksimal, masih awal dan sangat dini. Dari pemaparan diatas dapat dilihat hal-hal yang sama maupun yang berbeda. Persamaannya dari 4 karya tersebut ialah aspek mencampur. Sedang perbedaan dari masing-masing karya tersebut dapat dilihat pada tabel dibawah ini :

\begin{tabular}{|c|c|c|}
\hline Karya & Persamaan & Perbedaan \\
\hline 1. & & $\begin{array}{l}\text { Mencampur semua pathet pada laras } \\
\text { dengan vocal gerong-an. Pathet nem, } \\
\text { pathet lima, pathet barang (laras pelog). } \\
\text { Pathet sanga dan pathet manyura (laras } \\
\text { slendro). }\end{array}$ \\
\hline 2. & $\begin{array}{l}\text { Menggunakan } \\
\text { sistem } \\
\text { mencampur. }\end{array}$ & $\begin{array}{l}\text { Mencampur laras yang sama (laras } \\
\text { pelog) dengan menggunakan gamelan } \\
\text { yang berbeda (gamelan Jawa dan }\end{array}$ \\
\hline
\end{tabular}




\begin{tabular}{|c|l|l|}
\hline & \multicolumn{2}{|l|}{ gamelan Bali). } \\
\hline 3. & $\begin{array}{l}\text { Mencampur laras pelog dan slendro } \\
\text { beserta pathet-pathetnya dengan idiom } \\
\text { gamelan yang sama (gamelan Jawa) dan } \\
\text { vocal. }\end{array}$ \\
\hline 4 & $\begin{array}{l}\text { Melebur 2 laras yang berbeda (pelog dan } \\
\text { slendro) dalam 1 instrumen yang disusun } \\
\text { mirip dengan instrumen Gender. }\end{array}$ \\
\hline
\end{tabular}

Dapat dilihat dari kolom perbedaan pada tabel diatas, bahwa keterangan pathet pada laras wandu belum ada. Maka pada kesempatan kali ini, penulis akan merumuskan konsep pathet untuk Gender wandu dengan resep adaptasi dari deretan kempyung yang dituliskan secara sistematis oleh Sindu Sawarno.

\section{Realitas Nglebur Laras}

Nglebur Laras memiliki multi-interpretasi. Bisa dimaknai sebagai regenerasi sebuah seni dalam sebuah relevansi sosial budaya musik dan sosial budaya manusia. Gabungan dua kata tersebut dapat dimaknai lebih dan dipahami sebagai sinergi atau peleburan segenap rasa (puzzle rasa: jika boleh dipersepsikan bahwa penabuh merupakan satu bentuk puzzle, perekatnya adalah konsep garapan yang disatukan), mewujud kesatuan (unity), keselarasan, keharmonisan di bawah payung konsep garapan.

Suhastjarja, merupakan salah satu penulis tentang seni karawitan yang memiliki definisi yaitu musik Indonesia berlaras non diatonis (dalam laras slendro dan pelog) yang garapan-garapannya sudah menggunakan sistem notasi, warna suara, ritme, memiliki fungsi, sifat pathet, dan aturan garap dalam bentuk instrumentalia, vokalis dan campuran, enak didengar untuk dirinya maupun orang lain.

Kebutuhan untuk berprokreasi, guna melahirkan generasi berikutnya merupakan kekuatan yang dipergunakan sebagai dalih terhadap "anti naturalitas" dan "ketidakpantasan" (Colin Spencer:2011). Ungkapan yang tidak dapat dipungkiri, bahwa memang laras telah menjadi wajib dalam gamelan. Apa pun bentuk dari kebutuhan itu, pengolahan, fantasi dan kreasi, ibadah, ataupun bentuk dari keegoisan. Tegasnya adalah, laras digunakan untuk mengidentifikasikan perbedaan karakter yang rumit, sendu, duka, lincah, ceria dari segi sosial budaya karawitan. 


\section{Kedudukan Laras dalam pembentuk musik dengan laras campur}

Konsep penggarap musik nusantara dengan konten mencampur tersebut akan dipaparkan dalam bagan dibawah ini :

Bagian I
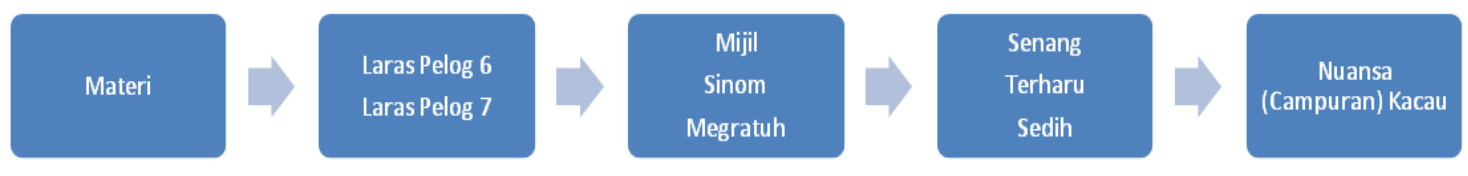

Bagian II
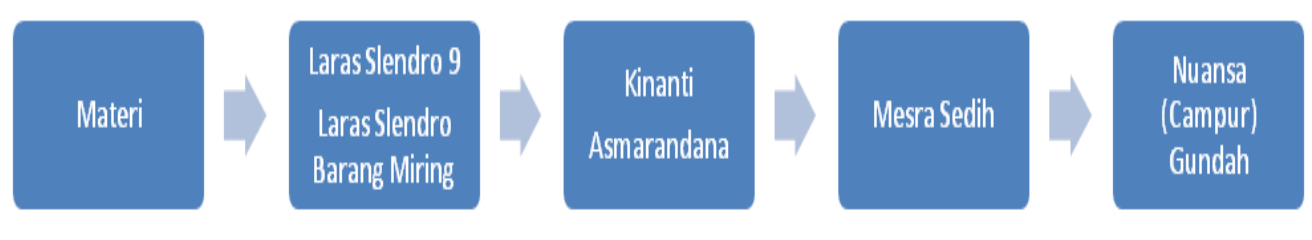

Bagian III

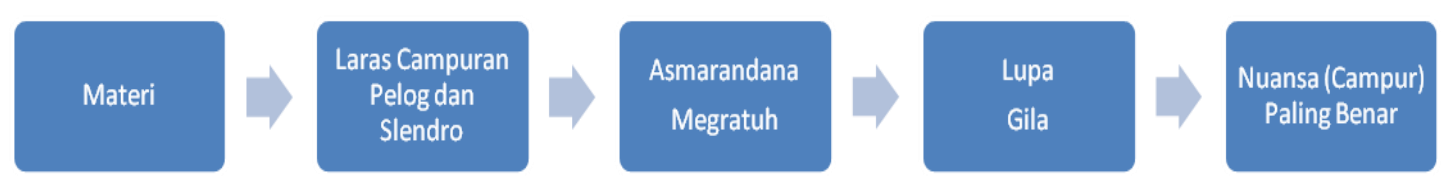

\section{Konsep Penciptaan}

Laras dalam dunia karawitan memiki tiga makna jamak yaitu, pertama; sesuatu yang (bersifat) 'enak atau nikmat untuk didengar atau dihayati, kedua; yaitu suara yang telah ditentukan jumlah frekuensinya (penunggul, gulu, dhadha, pelog, lima, nem dan barang). Makna yang ketiga adalah tangga nada atau scale, yaitu susunan nada-nada yang jumlah urutan dan pola interval nada-nadanya telah ditentukan. Rasa tersebut relevan dengan selera seperti ungkapan Rahayu Supanggah dalam bukunya Bothekan Karawitan I bahwa 'laras memang sangat erat dengan rasa, selera rasa dapat terbentuk oleh budaya, termasuk tradisi dan kebiasaan lokal' (Supanggah, 2002: 89).

Selain perihal laras, penulis memikirkan lebih dalam tentang pathet yang akan disusun. Secara esensial pathet juga salah satu jenis atau bentuk komposisi musikal yang terdapat dalam tradisi Karawitan gaya Surakarta. Kaitannya dalam penggarapan komposisi musik gamelan, pathet merupakan salah satu aturan yang mengikat pengrawit pada saat menabuh ricikannya atau melantunkan vokalnya. Menurut Rahayu Supanggah, pathet dibagi menjadi tiga dalam masing-masing laras. Jika laras pelog memiliki pathet 
lima, pathet nem, dan pathet barang, laras slendro memiliki pathet nem, pathet songo, dan pathet manyura. Secara sistematis Sindu Sawarno membuat deretan kempyung untuk mengetahui pathet pada masing-masing laras, dasar pathet menurut deret kempyung pada laras pelog pathet limo yang jadi acuan ialah:

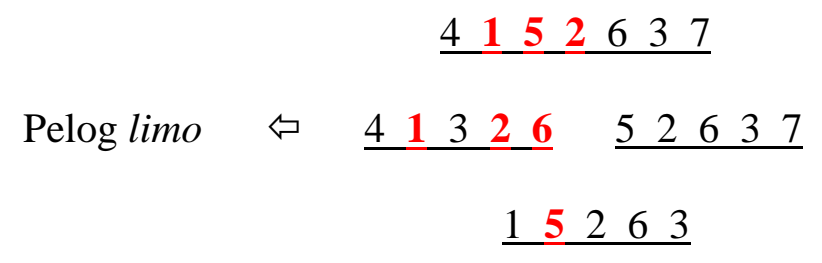

Deretan kempyung pelog pathet limo : 5 turun (nada tengah atas dengan tanda merah di baca keb arah bawah lurus) sebagai tonika, 1 (nada pertama atas bertanda merah dibaca kekiri bawah) sebagai dominan, 2 (nada belakang atas bertanda merah dibaca ke kiri bawah) sebagai sub-dominan, selanjutnya pada laras pelog pathet nem : (cara membaca keterangan sama dengan penentuan pathet 5).

\begin{tabular}{lllllll}
4 & 1 & 5 & 2 & 6 & 3 & 7 \\
\hline
\end{tabular}

$$
\begin{aligned}
& \begin{array}{llllllll}
41526 & 526 & 6
\end{array} \\
& 15263 \Rightarrow \text { Pelog nem }
\end{aligned}
$$

Deretan kempyung pelog pathet nem : 2 sebagai tonika, 5 sebagai dominan, 6 sebagai subdominan, dan pathet barang :

\section{$\begin{array}{lllllll}4 & 1 & 5 & 2 & 6 & 3 & 7\end{array}$}

$$
\begin{aligned}
& \begin{array}{lllllll}
41526 & \underline{52637} \\
15263
\end{array}
\end{aligned}
$$

Deretan kempyung pelog pathet barang : 6 (nada tengah atas bertanda merah dibaca ke arah bawah lurus) sebagai tonika, 2 (nada pertama bertanda merah dibaca kesamping bawah kanan) sebagai dominan, 3 (nada terakhir bertanda merah dibaca kesamping kanan bawah) sub-dominan.

Kemudian pada laras Slendro memiliki konsep deret kempyung demikian:

$$
\begin{array}{lllllll}
3 & 1 & 5 & 2 & 6 & 3 & 1 \\
\hline
\end{array}
$$




\section{$\underline{31526} \quad \underline{52} 63 \quad \Rightarrow$ Slendro manyura \\ $\begin{array}{lllll}15 & 2 & 6 & 3\end{array} \Rightarrow$ Pelog nem}

Deretan kempyung slendro pathet songo : 5 (nada tengah atas bertanda merah dibaca ke arah bawah lurus) sebagai tonika, 1 (nada pertama bertanda merah dibaca kesamping bawah kiri) sebagai dominan, 2 (nada pertama bertanda merah dibaca kesamping bawah kiri) sebagai sub-dominan. Selanjutnya pada laras slendro dilakukan dengan cara yang sama, berdasarkan deretan kempyung.

Laras slendro pathet nem sebagai berikut :

$\begin{array}{lllllll}3 & 1 & 5 & 2 & 6 & 3 & 1\end{array}$

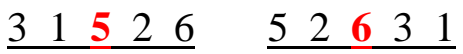 \\ $15263 \Rightarrow$ Slendro nem}

Slendro pathet nem : 2 (nada tengah atas bertanda merah dibaca kebawah lurus) sebagai tonika, 5 (nada pertama bertanda merah dibaca kebawah kiri) sebagai dominan, 6 (nada terakhir bertanda merah dibaca kebawah kanan) sebagai sub-dominan, dan pada laras slendro pathet manyura sebagai berikut :

\section{$\begin{array}{lllllll}3 & 1 & 5 & 2 & 6 & 3 & 1\end{array}$}

\section{$\begin{array}{llllllllll}3 & 1 & 5 & 2 & 6 & 5 & 2 & 6 & 3 & 1\end{array}$}

\section{$\underline{15263}$}

Slendro pathet manyura : 6 (nada tengah bertanda merah dibaca kebawah lurus) sebagai tonika, 2 (nada pertama bertanda merah dibaca kekanan bawah) sebagai dominan, 3 (nada terakhir bertanda merag dibaca kebawah kanan) sebagai sub-dominan. Rumusan tersebut diatas dijadikan landasan penulis untuk diaplikasikan ke konsep pathet pada gamelan Gender wandu.

budaya pulau Bali terdapat konsep keseimbangan hidup manusia yaitu dapat terwujud dalam beberapa dimensi, seperti: 1. Keseimbangan hidup manusia dalam dimensi tunggal, 2. Dimensi dualitas, 3. Dimensi tiga, 4. Dimensi empat, 5. Dimensi lima, 
6. Dimensi enam, 7. Dimensi tujuh, 8. Dimensi delapan, 9. Dimensi sembilan, dan 10. Dimensi sepuluh. Salah satu konsep tersebut, yang relevan dengan bahasan kali ini adalah konsep tiga. Konsep ini menunjuk kepada adanya unsur serba tiga dalam kehidupan seperti: trimurti (brahma, wisnu, siwa): tri loka (dunia bawah, dunia antara, dan dunia atas), tri aksara (ang, ong, mang), angka satu menuju angka dua diantaranya ada setengah, dan lain sebagainya. Salah satunya adalah konsep luh-muani dan bancih, lanang, wadon, dan kedi (Made Bandem,1987:11).

Searah dengan beberapa pengertian di atas, maka dapat dipahami pengertian konsep tiga (laras) sebagai tiga perwujudan kegagahan (diambuil dari karakter laras pelog), lembut, rumit, dan mudah sendu (diambil dari karakter laras slendro) dan campuran atas keduanya (baca: abu-abu). Wajib penulis meyakini ungkapan tersebut bahwa mereka mempunyai tiga wujud (sifat). Tiga sifat tersebut adalah kegagahan, kelembutan, serta kegagahan dan kelembutan menjadi satu (cross, bertemu atau bersilang dan menyatu).

Mengacu pada teori Karawitan Rahayu Supanggah pada bukunya Bothekan Karawitan II: GARAP, teori ini digunakan sebagai panduan untuk menggarap komposisi musik yang berpijak pada etnis Jawa. Teori tersebut diaplikasikan sebagai rambu-rambu dan penuntun ide-ide tahapan penciptaan. Buku pertama: Karawitan Bothekan II: GARAP ini berisikan tentang cara dan pengenalan garap pada konsep gamelan. Buku Rahayu Supanggah juga diterangkan metode penggarapan komposisi. Istilah-istilah 'garap' menurut Rahayu Supanggah ada tujuh yaitu; teknik, pola, irama dan laya, laras, pathet, konvensi, dan dinamika. Ketujuh jenis tersebut, penulis hanya menggunakan satu istilah yang akan digarap nantinya, yaitu: laras.

\section{Kesimpulan}

Dalam bahasan yang telah disampaikan, bahwa kegiatan mencampur apa pun termasuk yang dilakukan penulis memang tidak mudah. Seorang seniman pasti mengalami hambatan dalam proses berkarya. Hambatan bukanlah sebuah perang yang harus ditakuti, tetapi belajar menemukan kegagalan adalah petunjuk menuju jembatan yang akan mengantarkan ke titik tujuan sukses. Hambatan-hambatan yang datang kemudian berusaha mengganggu lancarnya proses dalam karya ini lebih banyak dikarenakan oleh minimnya waktu latihan. Waktu yang sudah dipertimbangkan secara matang ternyata sedikit meleset dengan apa yang diharapkan sebelumnya. Pada faktanya semua memang tidak seperti yang sudah direncanakan. Rumus yang sudah 
disiapkan, akan saja tetap berubah selayaknya perasaan manusia yang sering mempertimbangkan segala hal. Pertimbangan tersebut mempengaruhi sebuah penguasaan materi dari awal proses hingga pementasan.

\section{Daftar Pustaka}

Saidi, Acep Iwan. 2008. Narasi Simbolik Seni Rupa Kontemporer Indonesia. Yogyakarta: IsacBook.

Supanggah, Rahayu. 2002. Bothekan Karawitan I. Jakarta: Ford Foundation \& Masyarakat Seni Pertunjukan Indonesia.

Supanggah, Rahayu. 2009. Bothekan Karawitan II; GARAP. Surakarta: ISI Press.

Marianto, M. Dwi. 2006. Quantum Seni. Semarang: Dahara Prize.

Hadi, Y. Sumandiyo. 1990. Mencipta Lewat Tari. Yogyakarta: Institut Seni Indonesia Yogyakarta.

Hendarto, Sri. 2011. Organologi \& Akustika I \& II, Bandung : CV. Lubuk Agung 